\title{
Cognitive Behaviour Therapy for Children and Adults with Asperger's Syndrome
}

\author{
Tony Attwood \\ Griffith University, Australia
}

\begin{abstract}
Asperger's syndrome is a relatively newly diagnosed developmental disorder within the autistic spectrum. Children and adults with Asperger's syndrome have an intellectual ability within the normal range but due to their unusual profile of cognitive, social and emotional abilities are vulnerable to the development of a secondary mood disorder. This paper provides an explanation of the abilities associated with Asperger's syndrome, and modifications to cognitive behaviour therapy (CBT) for this very unusual client group. In particular, the paper emphasises the importance of affective education for this clinical population and describes a new strategy used in cognitive restructuring, namely, the emotional toolbox. The paper concludes with a brief description of a current evaluation study of the effectiveness of CBT to treat anxiety and anger in children who have Asperger's syndrome. However, the strategies described in this paper can also be used with adults with Asperger's syndrome and applied to other clinical populations.
\end{abstract}

In 1981, Lorna Wing first used the eponymous term Asperger's syndrome to describe children with an intellectual capacity within the normal range, but whose distinct profile of abilities is consistent with our understanding of autistic spectrum disorders. The profile of abilities includes the following characteristics that are based on the diagnostic criteria in DSM IV-TR (APA, 2000), recent research on Asperger's syndrome and the author's extensive clinical experience (Attwood, 1998):

A qualitative impairment in social interaction:

- failure to develop friendships that are appropriate to the child's developmental level

- impaired use of nonverbal behaviour such as eye gaze, facial expression and body language to regulate a social interaction

- lack of social and emotional reciprocity and empathy

- impaired ability to identify social cues and conventions.

A qualitative impairment in subtle communication skills:

- fluent speech but difficulties with conversation skills and a tendency to be pedantic, to have an unusual prosody and to make literal interpretations.

Address for correspondence: Tony Attwood PhD, The Asperger's Syndrome Clinic, PO Box 224, Petrie, Queensland 4502, Australia.E-mail: anthonyattwood@compuserve.com 
Restrictive interests:

- the development of special interests that are unusual in their intensity and focus

- preference for routine and consistency.

The disorder can also include motor clumsiness and a hypersensitivity to specific auditory and tactile experiences. There can also be problems with organisational and time management skills and explaining thoughts and feelings using speech. The exact prevalence rates have yet to be determined, but research suggests that it may be as common as one in 250 children (Gillberg, 2002). The precise etiology also has yet to be determined but is probably due to genetic and other factors that affect brain development and not due to emotional deprivation or other psychogenic factors. Recent research has indicated that $5 \%$ of children referred to child psychiatric clinics have signs of Asperger's syndrome (Gillberg, 2002), and $1.5 \%$ of adults referred to psychiatric outpatient clinics and $4 \%$ of adults referred to clinics for severe psychiatric disorders have signs of Asperger's syndrome (Nylander $\&$ Gillberg, 2001). Research also suggests that $16 \%$ of clients with adolescent-onset anorexia nervosa have signs of Asperger's syndrome (Wentz, Nilsson, et al., 1999) and $20 \%$ of clients with obsessive-compulsive disorder have traits of Asperger's syndrome (Bejerat, Nylander, \& Lindstrom 2001).

\section{High Incidence of Mood Disorders}

When one considers the diagnostic criteria and profile of abilities of children and adults with Asperger's syndrome, one would expect significant effects on the person's adaptive functioning, especially in a social context, and that such individuals would be vulnerable to the development of a secondary mood disorder. The current research indicates that around $65 \%$ of adolescents with Asperger's syndrome have an affective disorder that includes the range of anxiety disorders (Ghazuddin, Wieder-Mikhail, \& Ghaziuddin, 1998; Gillot, Furniss, \& Walter 2001; Green, Gilchrist, Burton, \& Cox, 2000; Kim \& Orlens, 2000; Tantam, 2000; Tonge, Brereton, Gray, \& Einfeld, 1999) and depression (Green et al., 2000). There is also evidence to suggest an association with delusional disorders (Kurita, 1999), paranoia (Blackshaw, Kinderman, Hare, \& Hatton, 2001) and conduct disorders (Tantam, 2000). Psychologists who specialise in a wide variety of client groups are likely to be referred a client for the treatment of a mood disorder and, after conducting a full developmental history, recognise and diagnose Asperger's syndrome. We know that comorbid mood disorders in children and adults with Asperger's syndrome are the rule rather than the exception but why should this population be more prone to mood disorders?

Research has been conducted on the family histories of children with autism and Asperger's syndrome and has identified a higher than expected incidence of mood disorders (Bolton, Pickles, Murphy, \& Rutter, 1998; De Long \& Dwyer, 1988; Ghaziuddin \& Greden, 1998; Piven \& Palmar, 1999). Individuals with Asperger's syndrome could be vulnerable to a genetic predisposition to mood disorders, and to modelling their thoughts and behaviour on a parent. However, when one also considers their difficulties with regard to social reasoning, empathy, verbal communication, profile of cognitive skills and sensory perception they are clearly prone to considerable stress. Thus, there may be constitutional and circumstantial factors that explain the higher incidence of affective disorders.

The theoretical models of autism developed within cognitive psychology, and research in neuropsychology also provide some explanation as to why such 
individuals are prone to secondary mood disorders. The extensive research on theory of mind skills confirms that individuals with Asperger's syndrome have considerable difficulty identifying and conceptualising the thoughts and feelings of other people and themselves (Baron-Cohen \& Joliffe, 1997; Baron-Cohen, O'Riordan, Stone, Jones, \& Plaisted, 1999; Heavey, Phillips, Baron-Cohen, \& Rutter, 2000; Kleinman, Marciano, \& Ault, 2001; Muris et al., 1999). The interpersonal and inner world of emotions appears to be uncharted territory for people with Asperger's syndrome.

Research on executive function in subjects with Asperger's syndrome suggests characteristics of being disinhibited and impulsive with a relative lack of insight that affects general functioning (Eisenmajer et al., 1996; Nyden, Gillberg, Hjelmquist, \& Heiman, 1999; Ozonoff, South, \& Miller, 2000; Pennington \& Ozonoff, 1996). Impaired executive function can also affect the cognitive control of emotions. Clinical experience indicates there is a tendency to react to emotional cues without cognitive reflection. Research with subjects with autism using new neuro-imaging technology has also identified structural and functional abnormalities of the amygdala (Adolphs, Sears, \& Piven, 2001; Baron-Cohen, Ring, Wheelwright, Bullmore, Brammer, Simmons, et al., 1999; Critchley et al., 2000; Fine, Lumsden, \& Blair, 2001), which is known to regulate a range of emotions including anger, fear and sadness. Thus we also have neuro-anatomical evidence that suggests there will be problems with the perception and regulation of the emotions.

\section{Modifications to Cognitive Behaviour Therapy}

Clinicians need to know how to modify standard psychological treatments in order to accommodate the unusual cognitive profile of people with Asperger's syndrome. As the primary psychological treatment for mood disorders is cognitive behaviour therapy (CBT), this paper will now examine such modifications based on our clinical knowledge of this developmental disorder.

\section{Affective education}

When one considers the theory of mind and empathy impairments associated with Asperger's syndrome, it is clearly apparent that affective education is an essential component of CBT for such clients. The main goal of such therapy is to inform the client why we have emotions, how such emotions are used and misused and to identify different levels of expression. A basic principle is to explore one emotion at a time as a theme for a project. The choice of which emotion to start with is decided by the clinical psychologist but a useful starting point is happiness or pleasure. A scrapbook can be created that illustrates the emotion. For young children this can include pictures of people expressing the different degrees of happiness or pleasure, but can be extended to pictures of objects and situations that have a personal association with the feeling, for example, this might be a photograph of a rare lizard for a person with a special interest in reptiles. For adults, the book can illustrate the pleasures in their life, with a list resembling the song 'My Favourite Things'. The content can also include the sensations that may elicit the feeling, such as sounds, aromas, tastes and textures. The scrapbook can be used as a diary to include compliments, and records of achievement such as certificates and memorabilia. At a later stage in therapy the scrapbook can be used to counteract a particular mood but it can also be used to illustrate different perceptions of a situation. If the CBT is conducted in a group, the books can be compared and contrasted. 
Talking about trains may be an enjoyable experience for one participant but perceived as remarkably boring or dominating for another. Part of the education is to explain that while this topic may create a feeling of wellbeing in the one participant, his or her attempt to cheer up another person by talking about trains may not be a successful strategy, perhaps producing an unexpected response. An interesting aspect that the author has noticed is that clients with Asperger's syndrome tend to achieve enjoyment primarily from knowledge, interests and solitary pursuits rather than from social experiences; they are often at their happiest when alone.

The affective education stage includes the clinical psychologist describing (and the client discovering) the salient cues that indicate a particular level of emotional expression in facial expression, tone of voice, body language and context. The face could be described as an information centre for emotions, but for the person with Asperger's syndrome typical errors in reading a face include not identifying which cues are relevant or redundant, and misinterpreting cues. The clinical psychologist uses a range of games and resources to 'spot the message' and explain the multiple meanings of expression: for example, a furrowed brow can mean anger or bewilderment, or may be a sign of ageing; a loud voice does not automatically mean that a person is angry.

Once the key elements that indicate a particular emotion have been identified, it is important to use an 'instrument' to measure the degree of intensity. The clinical psychologist can use a picture or drawing of a 'thermometer', 'gauge', or volume control and use a range of activities to illustrate the different degrees of expression. For example, a selection of pictures of happy faces can be used and each picture placed at the appropriate point on the thermometer. During the CBT program, it is important to ensure the client and psychologist share the same definition or interpretation of words and gestures, and to clarify any semantic confusion. Clinical experience has indicated that some clients with Asperger's syndrome can use extreme statements such as 'I am going to kill myself' to express a level of sadness that would be more moderately expressed by another client. During a program of affective education the clinical psychologist often has to increase the client's vocabulary of emotional expression to ensure precision and accuracy.

\section{Cognitive Restructuring}

Cognitive restructuring enables clients to correct distorted conceptualisations and dysfunctional beliefs. The process involves challenging their current thinking with logical evidence and ensuring the rationalisation and cognitive control of their emotions. The first stage is to establish the evidence for a particular belief. People with Asperger's syndrome can make false assumptions of their circumstances and the intentions of others. They have a tendency to literal interpretations, and a casual comment may be taken out of context or to the extreme. For example, a young teenage boy with Asperger's syndrome was once told his voice was breaking. He became extremely anxious that his voice was becoming faulty and decided to consciously alter the pitch of his voice to repair it. The result was an artificial falsetto voice, which was quite incongruous in a young man. A teenage girl with Asperger's syndrome overheard a conversation at school that implied that a girl must be slim to be popular; she then achieved a dramatic weight loss in an attempt to be accepted by her peers. We are all vulnerable to distorted conceptualisations but people with Asperger's syndrome are less able to put things in perspective, seek clarification and/or consider alternative explanations or responses. The clinical 
psychologist encourages the client to have more flexible thinking and to seek clarification using questions or comments such as 'Are you joking?' or 'I'm confused about what you just said'. Such comments can also be used when misinterpreting someone's intentions, for example, 'Did you do that deliberately?', and to rescue the situation after the client has made an inappropriate response with a comment such as, 'I'm sorry I offended you' or 'Oh dear, what should I have done?'

To explain a new perspective or to correct errors or assumptions, 'comic strip conversations' can help the client determine the thoughts, beliefs, knowledge and intentions of the participants in a given situation (Gray, 1998). This technique involves drawing an event or sequence of events using a storyboard approach with stick figures to represent each participant, and speech, thought and feeling bubbles to represent words, thoughts and emotions. The client and psychologist use an assortment of fibre-tipped coloured pens, with each colour representing an emotion. As each speech or thought bubble is filled in, the person's choice of colour indicates his or her perception of the emotion conveyed or intended. This can clarify the client's interpretation of events and the rationale for his or her thoughts and response. This technique can help the client identify and correct any misperception and determine how alternative responses will affect subsequent thoughts and feelings.

The author has developed a particularly useful strategy for cognitive restructuring that is being developed and evaluated in his clinical practice, and could also be used with other client groups.

\section{The Emotional Toolbox}

From an early age, children will know a toolbox contains a variety of different tools to repair a machine or fix a household problem. The strategy developed by the author is to identify different types of 'tools' to fix the problems associated with negative emotions, especially anxiety, anger and sadness. The range of tools can be divided into those that constructively release or reduce energy and those that improve thinking. The author works with the child and family or adult with Asperger's syndrome to identify different tools that help fix the feeling as well as some tools that can make the emotions or consequences worse. The participants use paper and pens during a brainstorming session during which they draw a toolbox and pictures and descriptions of different types of tools and activities that can encourage constructive emotion management.

\section{Physical Tools}

A hammer can represent tools or actions that physically release energy. A picture of a hammer is drawn on a large sheet of paper and participants suggest safe physical activities. For young children this may include going for a run, bouncing on the trampoline or going on a swing. For older children and adults, sports practice and dancing may be used to 'let off steam'. For example, a child nominated a game of tennis as one of his physical tools as it 'takes the fight out of me'. Other activities include cycling, swimming and playing the drums. Some household activities can provide a satisfying release of energy without expensive repairs, for example, recycling, where cans or packaging are crushed, or old clothes are torn up to make rags, can be the tool to repair the feelings of frustration. Kitchen activities can include 
squeezing oranges or pounding meat. Adults may consider some aspect of gardening or renovations.

Some children and adults with Asperger's syndrome may have already identified that destruction as a physical tool is a very effective 'quick fix' to end the feeling but have not been careful in choosing the focus of their physical release. If something is to be broken to release stress, it is preferable that the energy is channelled into a constructive activity. The author uses the term 'creative destruction' to describe some recycling activities that effectively release energy.

\section{Relaxation Tools}

Relaxation tools help to calm the person and lower the heart rate. A paintbrush could be used to illustrate this category of tools, and activities could include drawing, reading and listening to music. People with Asperger's syndrome often find that solitude is their most relaxing activity. They may need to retreat to a quiet, secluded sanctuary as an effective emotional repair mechanism. Young children may relax by using gentle rocking actions, singing and engaging in a repetitive action; this can include manipulating an object such as a stress ball that has the same soothing qualities as an adult manipulating worry beads.

Other relaxing activities can include massage, a brief doze or good sleep as well as applying previously practised relaxation activities that focus on breathing and imagery. For adults, a routine chore such as making the house clean and tidy can be a repetitive action that results in satisfaction and relaxation when complete. Obviously there are problems if this is the dominant tool in the toolbox and becomes the focus for an obsessive-compulsive disorder. Teachers may also use this strategy: when they notice the child is becoming distressed, they can suggest a high status responsibility that will enable the child to leave a situation or to become distracted by an activity that restores order and consistency. For example, the teacher could suggest that the child leaves the class to take an important message or document to the school office or tidies the book cupboard and places all the books in alphabetical order. An adult with Asperger's syndrome may nominate his or her own relaxation tools for use at work and at home.

\section{Social Tools}

This group of tools uses people as a means of managing feelings. The goal is to find and be with someone who can help change the mood. A two-handle saw can be used to represent social activities or individuals who can repair feelings. The social activity will need to be enjoyable and without the stress that can sometimes be associated with social interaction. The supportive social contact can include seeking and being with someone who genuinely admires or loves the child or adult, gives compliments and manages to say the right things to repair the feelings. This can be a family member - perhaps a grandparent who has time to be patient with the child - or a friend, but remember that sometimes two is company, three a crowd. Children and adults with Asperger's syndrome are more likely to have success with a one-on-one interaction. Communication using Internet chat lines can be a successful social activity that can be an emotional repair mechanism. People with Asperger's syndrome may have greater eloquence and insight in disclosing their thoughts and feelings by typing rather than talking. One does not need skills with eye contact and reading a face or changes in vocal tone or body language when engaged in a 'conversation' on the Internet. The chat line can include other 
people with Asperger's syndrome who have genuine empathy and may offer constructive suggestions to repair a mood or situation. The author has known several mature adults with Asperger's syndrome who have provided wise support and advice for younger members of the 'Asperger community'.

Sometimes the best 'friend' may be a pet. Dogs are always delighted to see their owner, show unconditional adoration and enjoy the person's company. A positive action that may help to repair negative emotions is to help someone or to be needed - an altruistic act. The author has noted that some children, and especially, adults with Asperger's syndrome can change their mood when helping others. This can include activities such as helping someone who has difficulties in an area of the child's talents or expertise, for example, helping an adult negotiate or fix a problem with a computer or guiding another classmate who does not have the child's ability with a subject such as mathematics. Adults with Asperger's syndrome can enjoy volunteer work, particularly with the elderly, very young children and animals. Being needed and appreciated is a significant emotional repair mechanism for all of us, including those with Asperger's syndrome.

\section{Thinking Tools}

The client can nominate another type of tool, such as a screwdriver or wrench, to represent a category of tools that can be used to change thinking or knowledge. The client is encouraged to use his or her intellectual strength to control feelings using a variety of techniques. Self-talk can be used, such as, 'I can control my feelings' or, 'I can stay calm', when under stress. The words can be reassuring and encourage self-esteem. In her description of her family, with its three generations of people with Asperger's syndrome, Liane Holliday Willey (2001), who herself has Asperger's syndrome, has created a series of statements such as, 'I will ask for help when I need it'and 'I will be patient with those who need time to understand me'. Evan, a young man with Asperger's syndrome, was discussing thinking tools with the author and created the strategy of making an 'antidote to poisonous thoughts'. The procedure is to provide a comment that counteracts negative thoughts. For example, the thought, 'I can't do it' (poisonous thought) can be neutralised by the antidote, 'the smart thing to do is ask for help'. It is necessary to determine the person's negative or poisonous thoughts in a particular situation and create a personalised antidote that is remembered or written on a card carried by the client to be 'administered' when needed.

Another thinking tool is to put the event in perspective: a reality check. The approach is to use logic and facts with a series of questions such as, 'Is there another shop where we could buy that particular computer game?' or 'Will children teasing you about your interest in astronomy prevent you from being a successful astronomer?'

Children and adults with Asperger's syndrome have a great interest in acquiring knowledge and a special type of 'thinking tool' is to create a project on the source of stress. For example, one source of extreme distress may be the sound of a handdryer. The project can include dismantling a hand-dryer to see how it works and being reassured that it switches off after people have dried their hands. There can be a comparison of different dryer models and exploration of which rest rooms have a dryer. For children, the project can be written as a science project or a 'social story' (Gray, 1998). 
One thinking tool that can be used by children with Asperger's syndrome to improve mood and self-esteem is achieving academic success, which may not be the choice of other children. When children with Asperger's syndrome are stressed, the teacher may instruct them to complete a school activity that they enjoy and for which they have a natural talent. As many children with Asperger's syndrome enjoy completing and getting correct classroom activities (such as solving mathematic problems or spelling), then this may be the preferred activity, and this tool can be suggested when they are stressed so that they can achieve success and self-confidence. Other children would probably try to avoid academic tasks when stressed.

Cue-controlled relaxation is also a useful thinking tool. The strategy is for children to have an object in their pocket that symbolises relaxation (or to which through classical conditioning they respond by feeling relaxed). For example, a teenage girl with Asperger's syndrome was an avid reader of fiction, her favourite book being The Secret Garden. She kept a key in her pocket to metaphorically open the door to the secret garden, an imaginary place where she felt relaxed and happy. A few moments touching or looking at the key helped her to contemplate a scene described in the book and to relax and achieve a more positive state of mind. Adults can have a special picture in their wallet such as a photograph of a woodland scene, which reminds them of solitude and tranquillity.

\section{Special Interest Tools}

The recent survey of special interests examined the role the interest plays in the lives of the people with Asperger's syndrome (Bashe \& Kirby 2001). The major functions were an experience of intense enjoyment, security, comfort and relaxation and the facilitation or avoidance of social interaction. For children and adults with Asperger's syndrome, finding a rare specimen of the interest can be experienced as an intensely pleasurable moment, an 'intellectual orgasm'. This may be in contrast to a lack of enjoyment with social interaction. People with Asperger's syndrome may have relatively fewer pleasures in life and the special interest can be the 'silver lining' to a somewhat gloomy life - a natural antidepressant.

In the general population, rituals and repetition are commonly used to reduce anxiety. One of the characteristics of the special interests of people with Asperger's syndrome is their repetitive and ritualistic nature. An adolescent known to the author had a great interest in Japanese culture and performed the elaborate and ritualised Japanese tea ceremony whenever she felt anxious. Luke Jackson (2003), a teenager with Asperger's syndrome, describes the cataloguing of the examples of his interests as a means of 'personal defrag'. If one is considering imagery as part of a CBT program, then children and adults with Asperger's syndrome could be encouraged to think of their special interest.

In behavioural learning theory terms, the repetitive action, thought or interest becomes a form of negative reinforcement; it is soothing and therefore something to do to feel calmer. It is interesting that the degree of motivation and duration of time spent on the interest is proportional to the degree of stress (Bashe \& Kirby 2001). The more the person experiences stressors such as change, failure, and low selfesteem, the more the interest becomes obtrusive, dominant or bizarre. If the child or adult with Asperger's syndrome has few means of enjoyment and relaxation, what may have started as a source of pleasure and tranquillity can become under conditions of stress a compulsive act reminiscent of an obsessive-compulsive disorder. This problem can occur when clients have very few tools in their emotional tool- 
box. If the special interest is their only source of relaxation or escape, then the interest can become irresistible. Being prevented from achieving uninterrupted access to their only emotional restorative creates even more stress. A program of controlled or timed access can be introduced to ensure the time spent on the interest is not excessive. Unfortunately, from the clients' point of view, time goes quickly when you are enjoying yourself. There may need to be some negotiation and compromise regarding the duration of access. The special interest can be a useful tool in the toolbox, but must be just one of many tools.

\section{Other Tools}

There are other types or categories of tools that can be included in the toolbox, which may be typical of the general population, or unique.

Medication is often prescribed to manage or repair emotions. If the child or adult is showing clear signs of an anxiety disorder or depression, then medication can be recommended as a potential tool of emotion management. Some children and adults with Asperger's syndrome also have signs of attention deficit disorder. One of the characteristics of a combination of the two disorders is for the child to react impulsively when experiencing emotional arousal. Such children have a tendency to react without cognitive reflection, such as retaliating to an act of another child that caused emotional discomfort without first checking if the act was accidental or considering the consequences of retaliation. A trial of stimulant medication may reduce emotionally impulsive reactions.

Some children with Asperger's syndrome have a fluctuation of emotions that is cyclical. A mood diary can determine the amplitude and wavelength of any cyclical pattern and the administration of an anticonvulsant or medication to treat bipolar disorders could achieve a reduction in amplitude so that the client does not experience the extremes of emotion.

When the concern is anger, emotion management can be conceptualised as 'energy management' and antipsychotic medication can reduce the client's energy levels. The medication is prescribed as a sedative, not to treat signs of schizophrenia.

Clinical experience has confirmed the value of medication but there are some concerns, often voiced by parents and clients themselves. One concern is that at present we do not have longitudinal studies of the long-term effect of using psychotropic medication on young children. Another concern is the effect on the client's clarity of thought. From the author's clinical experience, many children and adults with Asperger's syndrome report that medication slows their thinking and cognitive skills. People with Asperger's syndrome often value their clarity of thought. As one adult with Asperger's syndrome described his reaction to medication, 'It was like I was locked out of my own home.' The medication not only improves the low moods, it can also reduce the exhilaration experienced during time spent on the special interest. There can therefore be a problem of client compliance in taking the medication consistently. However, as a matter of practicality, expediency, and in the absence of psychological therapies, medication may be the primary tool offered by health services.

Other potential tools are enjoyable activities, such as watching a favourite comedy: laughter is the best medicine. Children with Asperger's syndrome can enjoy jokes typical of their developmental level and be remarkably creative with puns and jokes (Werth, Perkins, \& Boucher, 2001). Another tool is to read the autobiographies of adults with Asperger's syndrome for encouragement and advice. 
We now have several autobiographies written by children and adults with Asperger's syndrome, which readers have found particularly inspirational.

Another tool category, which could be described as an environmental tool, involves the assessment of the person's sensory world, identifying strategies to avoid specific sensory experiences. For example, the position of the child's desk in class or the adult's work station may be assessed, and if necessary moved to reduce the general level of noise, distraction and interruption. Sensory Integration therapy or the use of Irlen lenses can reduce the distress caused by aspects of hypersensory perception that may be a characteristic of Asperger's syndrome and can be the focus of a phobia. In this instance, the client is anxious to avoid situations that pose a risk of experiencing the pain associated with a specific sensory experience, for example, he or she may avoid dogs due to a fear of hearing a dog bark.

A tool that can encourage self-control is the offer of a prize or reward. The reward can be to earn access to preferred activities, the special interest or even money. The author has noted that some children with Asperger's syndrome are natural capitalists. If the child is having organisational problems or has impaired executive function, then there will need to be strategies and support at school and especially at home when engaged in homework

A tool that can be used for some children, especially girls with Asperger's syndrome, is to act the part of a person they know or admire who could cope with the situation. In high school, speech and drama classes can be used to practise and roleplay what to do and think in specific situations. Some teenagers with Asperger's syndrome (especially girls) have used drama training and acting abilities to achieve social success. An example of this is the experience of Liane Holiday Willey, whose autobiography is titled Pretending to be Normal (Holiday Willey, 1999).

The concept of a toolbox can also be extended and used in group activities to compare the effectiveness of tools used by different participants in the group, presenting the possibility of 'borrowing' a tool.

An interesting and extremely valuable by-product of the toolbox strategy is that it can teach children and adults with Asperger's syndrome how to repair not only their own emotions, but those of their family members and friends.

\section{Inappropriate Tools}

Discussion of inappropriate tools (with the comment that one would not use a hammer to fix a computer) is necessary in order to explain how some actions, such as violence, thoughts of suicide and engaging in retaliation are not appropriate tools or emotional repair mechanisms. For example, one client known to the author would slap himself to stop negative thoughts and feelings. Another tool that could become inappropriate is the retreat into a fantasy world (perhaps imagining being a superhero). The use of escape into fantasy literature and games can be a typical tool for ordinary adolescents but is of concern when this becomes the dominant or exclusive coping mechanism. The border between fantasy and reality may become unclear — thinking may become delusional — leading to concern regarding the development of signs of schizophrenia. The psychologist also needs to consider whether teenagers or adults with Asperger's syndrome are using drugs and alcohol to manage their stress levels and mood, and whether prescription medication would be more effective and safer, as well as legal. Other inappropriate tools could include taking their stress out on someone, self-injury and the destruction of something valuable or precious. 
It is also necessary to evaluate tools used by parents, family members and teachers and to remove from the toolbox those that may be inappropriate or counterproductive. Children and adults with Asperger's syndrome are often confused by certain emotions and this can be the case with the expression of affection. They may fear what they do not easily understand and affection from others may not be an effective mechanism to repair their feelings. A teenage boy with Asperger's syndrome said, 'I get angry when someone tries to cheer me up', and a younger child, when asked if a hug would help when he was upset, replied with an emphatic, 'No, I get madder'. Children and adults with Asperger's syndrome can perceive gestures of affection as uncomfortable and not comforting; they may be annoyed that they are being squeezed or confused as to why someone would want to kiss their cheek. Parents, friends, family members and teachers will need to be aware that affection is a very powerful emotional restoration tool for themselves but not necessarily for children and adults with Asperger's syndrome. Demonstrating affection could 'add fuel to the fire'. Social stories, developed by Carol Gray, or information and discussion with the psychologist can be used to explain why other people respond to their distress by gestures and words of affection. This can reduce their confusion and increase their tolerance of affectionate behaviour in others. Sometimes affection can be used as an emotion repair mechanism or tool in the toolbox but the level of expression may be much less demonstrative than would be used with someone who does not have Asperger's syndrome.

\section{Unusual Tools}

Unusual tools or responses are also considered. The person with Asperger's syndrome may laugh when expected to show remorse (Berthier, 1995). Crying and laughing are both tension release mechanisms; unfortunately, the person with Asperger's syndrome may not know or be able to recognise which release mechanism is appropriate for the social context. Another example of an unusual response was explained during a group session on sadness: a teenage girl with Asperger's syndrome explained, 'Crying doesn't work for me, so I get angry'. Clinical experience suggests that tears may be rare as a response to feeling sad, with a more common response being anger. The program includes the development of a range of conventional means of emotional expression and repair mechanisms and an explanation as to why some reactions are misinterpreted by others.

Another tool or mechanism that appears to be unusual is that of being quick at resolving grief and anger. This characteristic can be of concern to the person's family who expect the classic signs of prolonged and intense grieving; they consider the person uncaring. This can also occur with anger, where the person with Asperger's syndrome may quickly express intense anger, which then ends as quickly as it began. However, this rapid recovery in both grief and anger is simply a feature of Asperger's syndrome.

Clinical experience with the concept of an emotional toolbox has provided some interesting comparisons between children with Asperger's syndrome and typical children who naturally have a much wider range of tools, the most popular and effective being social tools. For children with Asperger's syndrome, physical acts are often the first tool to be employed, to quickly and effectively discharge the emotion; emotion management is usually achieved by actions rather than reflection and relaxation. These children often need active encouragement to develop and use other people as a means of repairing their feelings. 


\section{Research on CBT and Clients With Asperger's Syndrome}

CBT has been refined and evaluated over several decades but has only recently been applied to children and adults with Asperger's syndrome (Attwood, 2003; Hare, 2004; Hare \& Paine, 1997; Reaven \& Hepburn, 2003). To date, we have remarkably few systematic and vigorous published research studies or case studies that have examined whether CBT is an effective treatment within the clinical population. However, the author and Kate Sofronoff at the University of Queensland are currently conducting a study of the effectiveness of two CBT programs with children with Asperger's syndrome between the ages of 10 and 12 years. The first program encourages the management of anxiety, the second the management of anger.

In the study on anxiety management, 79 children with Asperger's syndrome were recruited to participate in a controlled trial of a six-week intervention program. Children were randomly assigned to either the experimental or waiting-list control group. The program was conducted over six consecutive weeks and each session lasted for two hours. The program included affective education and cognitive restructuring using the strategies developed by the author, such as the emotional toolbox and the concept of a thermometer to measure the degree of emotion. The program also included activities developed by Carol Gray, namely social stories and comic strip conversations (Gray, 1998). Each participant had a workbook for each of the six sessions. The workbook included information, graphics, and questions with space for the participants' answers and strategies. At the end of each workbook there was a description of the project to be undertaken by the participant before the next session. The program was designed to be informative, interactive and entertaining. The author prepared trainer's notes to provide instructions on the nature, purpose, duration and style of each activity, as well as a list of resource material. Also included in the notes were strategies that are particularly useful when working with children with Asperger's syndrome, such as being careful with idioms, emphasising success and discovery, and avoiding criticism. Sessions two to six began with a summary and handout of the key points from the previous session.

In the first intervention, 24 children were divided into eight groups of three; two psychologists, interns in their second year of postgraduate clinical training at the University of Queensland, conducted each group. Parents were not involved in the sessions, but were encouraged to take the two hours to relax and have a chat and a cup of coffee. At the end of each session, the psychologists met briefly with the parents to let them know what had occurred and to ask for their help with the home-based project.

In the second intervention, 27 children were divided into nine groups of three with two psychologists per group. Parents in this intervention were asked to stay as a group and psychologists worked through the program with them at the same time as the child sessions were taking place. Parents were again encouraged to help their child with the home-based projects. The 28 children and parents in the waiting-list control group completed all assessments at the same time as the intervention groups and were then invited to participate in the program.

The assessments included several standardised measures of anxiety in childhood, including the Spence Children's Anxiety Scale (Spence, 1997) and the Social Worries Questionnaire (Spence, 1995). The author designed a new measure specifically for the study called 'James and The Maths Test'. A scenario was read by the child and he or she was asked to generate strategies for James to manage his 
anxiety. This measure was given to all children at preintervention, postintervention and six-week follow-up. 'James and the Maths Test' had a scoring system whereby one point was allocated for each positive strategy generated. Another measure was a parent report measure of self-efficacy in the management of specific behaviours related to Asperger syndrome (Sofronoff \& Farbotko, 2002). The questionnaire contains 15 behaviours and parents indicate which behaviours have occurred in the past two weeks and then indicate on a scale (0-5) how confident they are in their ability to manage the behaviour. The scale yields a mean score taken across the behaviours nominated to have occurred.

The author and Kate Sofronoff are currently examining the data generated during the above study and the data and results of a second study using a similar design and number of subjects. The second study is an evaluation of a CBT program for the management of anger. The preliminary analysis of results for both studies suggests significant differences between intervention and control groups on standardised measures, the new test to measure the child's ability to generate strategies and other measures completed by parents. Both studies appear to confirm the effectiveness of CBT as a treatment for anxiety and anger in this clinical population and the value of including parents in the implementation of the treatment program. Several papers on the study should be published in 2005 and further information can be obtained from the author.

\section{References}

Adolphs, R., Sears, L., \& Piven, J. (2001). Abnormal processing of social information from faces in autism. Journal of Cognitive Neuroscience, 13, 232-240.

American Psychiatric Association (APA). (2000). Diagnostic and statistical manual of mental disorders (4th ed., text revision). Washington, DC: Author.

Attwood, T. (1998) Asperger's syndrome: A Guide for Parents and Professionals. London: Jessica Kingsley.

Attwood, T. (2003) Frameworks for behavioral interventions. Child and Adolescent Psychiatric Clinics of North America, 12, 65-86.

Baron-Cohen, S., \& Joliffe, T. (1997). Another advanced test of theory of mind: Evidence from very high functioning adults with autism or Asperger's disorder. Journal of Child Psychology and Psychiatry, 38, 813-822.

Baron-Cohen, S., O'Riordan, M., Stone, V., Jones, R., \& Plaisted, K. (1999) Recognition of faux pas by normally developing children and children with autism and Asperger's disorder. Journal of Autism and Developmental Disorders, 29, 407-418.

Baron-Cohen, S., Ring, H.A., Wheelwright, S., Bullmore, E.T., Brammer, M.J., Simmons, A., et al. (1999). Social intelligence in the normal autistic brain: An FMRI study. Journal of Neuroscience, 11, 1891-1898.

Bashe, P., \& Kirby, B.L. (2001). The oasis guide to Asperger's syndrome. New York: Crown.

Bejerat, S., Nylander, L., \& Lindstrom, E. (2001) Autistic traits in obsessive-compulsive disorders. Nordic Journal of Psychiatry, 55, 169-176.

Berthier, M.L. (1995). Hypomania following bereavement in Asperger's disorder: A case study. Neuropsychiatry, Neuropsychology and Behavioural Neurology, 8, 222-228.

Blackshaw, A.J., Kinderman, P., Hare, D.J., \& Hatton, C. (2001). Theory of mind, casual attribution and paranoia in Asperger disorder. Autism, 5, 147-163.

Bolton, P., Pickles, A., Murphy, M., \& Rutter, M. (1998). Autism affective and other psychiatric disorders: Patterns of familial aggregation. Psychological Medicine, 28, 385-395.

Critchley, H.D., Daly, E.M., Bullmore, E.T., Williams, S.C.R., Van Amelsvoort, T., Robertson, D.M., et al. (2000). The functional neuroanatomy of social behaviour. Brain, 123, 2203-2212. 
De Long, G.R., \& Dwyer, J.T. (1988). Correlation of family history with specific autistic subgroups: Asperger's disorder and bipolar affective disease. Journal of Autism and Developmental Disorders, 18, 593-600.

Eisenmajer, R., Prior, M., Leekman, S., Wing, L., Gould, J., Welham, M., et al. (1996) Comparison of clinical symptoms in autism and Asperger's disorder. Journal of the American Academy of Child and Adolescent Psychiatry, 35, 1523-1531.

Fine, C., Lumsden, J., \& Blair, R.J.R. (2001). Dissociation between 'theory of mind' and executive functions in a patient with early left amygdala damage. Brain Journal of Neurology, 124, 287-298.

Ghaziuddin, M., \& Greden, J. (1998). Depression in children with autism/pervasive developmental disorders: A case control family history. Journal of Autism and Developmental Disorders, 28, $111-115$.

Ghazuddin, M., Wieder-Mikhail, W., \& Ghaziuddin, N. (1998). Comorbidity of Asperger syndrome: A preliminary report. Journal of Intellectual Disability Research, 42, 279-283.

Gillberg, C.A. (2002). Guide to Asperger syndrome. Cambridge, UK: Cambridge University Press.

Gillot, A., Furniss, F., \& Walter, A. (2001). Anxiety in high-functioning children with autism. Autism, 5(3), 277-286.

Graham, P. (1998). Cognitive behaviour therapy for children and families. Cambridge, UK: Cambridge University Press.

Gray, C. (1998). Social stories and comic strip conversations with students with Asperger syndrome and high-functioning autism. In E. Schopler, G.B. Mesibov, \& L.J. Kunce (Eds.), Asperger syndrome or high-functioning autism? New York: Plenum Press.

Green, J., Gilchrist, A., Burton, D., \& Cox, A. (2000). Social and psychiatric functioning in adolescents with Asperger disorder compared with conduct disorder. Journal of Autism and Developmental Disorders, 30, 279-293.

Hare, J.D. (2004). Developing cognitive behavioural work with people with ASD. Good Autism Practice, 5, 18-22.

Hare, D.J., \& Paine, C. (1997). Developing cognitive behavioural treatments for people with Asperger's syndrome. Clinical Psychology Forum, 110, 5-8.

Heavey, L., Phillips, W., Baron-Cohen, S., \& Rutter, M. (2000). The awkward moments test: A naturalistic measure of social understanding in autism. Journal of Autism and Developmental Disorders, 30, 225-236.

Holliday Willey, L. (1999). Pretending to be normal: Living with Asperger's syndrome. London: Jessica Kingsley.

Holliday Willey, L. (2001). Asperger syndrome in the family: Redefining normal. London: Jessica Kingsley.

Jackson, L. (2002). Freaks, geeks and Asperger's syndrome: A User Guide to Adolescence. London: Jessica Kingsley .

Kim, K.A., Szatmari, P., Bryson, S.E., Streiner, D.L., \& Wilson, F. (2000). The prevalence of anxiety and mood problems among children with autism and Asperger's disorder. Autism, 4, 117-132.

Kleinman, J., Marciano, P., \& Ault, R. (2001). Advanced theory of mind in high-functioning adults with autism. Journal of Autism and Developmental Disorders, 31, 29-36.

Kurita, H. (1999). Brief report: Delusional disorder in a male adolescent with high-functioning PDDNOS. Journal of Autism and Developmental Disorders, 29, 419-423.

Muris, P., Steerneman, P., Meesters, C., Merckelbach, H., Horselenberg, R., Van Den Hogan, T., et al. (1999). The TOM Test: A new instrument for assessing theory of mind in normal children and children with pervasive developmental disorders. Autism and Developmental Disorders, $29,67-80$.

Nyden, A., Gillberg, C., Hjelmquist, E., \& Heiman, M. (1999). Executive function/attention deficits in boys with Asperger disorder, attention disorder and reading/writing disorder. Autism, 3, 213-228.

Nylander, L., \& Gillberg, C. (2001). Screening for autism spectrum disorders in adult psychiatric outpatients. Acta Psychiatrica: Scandanaica, 103, 428-434. 
Ozonoff, S., South, M., \& Miller, J. (2000). DSM-IV defined Asperger disorder: Cognitive, behavioral and early history differentiation from high-functioning autism. Autism, 4, $29-46$.

Pennington, B.F., \& Ozonoff, S. (1996). Executive functions and developmental psychopathology. Journal of Child Psychology and Psychiatry Annual Research Review, 37, 51-87.

Piven, J., \& Palmar, R. (1999). Psychological disorder and the broad autism phenotype: Evidence from a family study of multiple-incidence autism families. American Journal of Psychiatry, 156, $557-563$.

Reaven, J., \& Hepburn, S. (2003). Cognitive-behavioral treatment of obsessive-compulsive disorder in a young child with Asperger syndrome. Autism, 7, 145-164.

Spence, S.H. (1995). The Social Worries Questionnaire. Social skills training: Enhancing social competence with children and adolescents. Windsor, UK: NFER-Nelson.

Spence, S.H. (1997). The Spence Children's Anxiety Scale. In I. Sclare (Ed.), Child psychology portfolio. Windsor, UK: NFER-Nelson.

Sofronoff, K., \& Farbotko, M. (2002) The effectiveness of parent management training to increase self-efficacy in parents of children with Asperger syndrome. Autism, 6, 271-286.

Tantam, D. (2000). Psychological disorder in adolescents and adults with Asperger disorder. Autism, 4, 47-62.

Tonge, B., Brereton, A., Gray, K., Einfeld, S., (1999). Behavioural and emotional disturbance in high-functioning autism and Asperger's disorder. Autism, 3, 117-130.

Wentz Nilsson, E., Gillberg, C., Gillberg, C., \& Rastam, M. (1999). Ten year follow up of adolescent-onset anorexia nervosa: Personality disorders. Journal of the American Academy of Child and Adolescent Psychiatry, 38, 1389-1395.

Werth, A., Perkins, M., \& Boucher, J. (2001). Here's the weavery looming up. Autism, 5(2), 111-125.

Wing, L. (1981). Asperger's syndrome: A clinical account. Psychological Medicine, 11, 115-129. 